\section{Visual Assessments of Biodegradable Mulch Deterioration Are Not Indicative of Changes in Mechanical Properties}

\author{
Jeremy S. Cowan ${ }^{1}$ \\ Washington State University, WSU Spokane County Extension, $222 \mathrm{~N}$. \\ Havana St., Spokane, WA 99202
}

Arnold M. Saxton

The University of Tennessee Institute of Agriculture, Knoxville, TN 37996

Hang Liu

Department of Apparel, Merchandising, Design and Textiles, Washington State University, Pullman, WA 99164

Karen K. Leonas

Textile and Apparel, Technology and Management, North Carolina State University, 2401 Research Drive, Raleigh, NC 27695

Debra Inglis
Department of Plant Pathology, Washington State University, 16650 State
Route 536, Mount Vernon, WA 98273-4768

Carol A. Miles

Department of Horticulture, Washington State University, 16650 State Route 536, Mount Vernon, WA 98273-4768

Additional index words. biodegradable plastic, biodegradation, mechanical properties, plastic mulch, tomato

Abstract. The functionality of biodegradable mulch can be evaluated in agricultural field settings by visually assessing mulch intactness over time (a measure of deterioration), but it is unclear if mulch deterioration is indicative of mulch degradation as measured by mechanical properties (like breaking force and elongation). This 3-year study (2010-12) examined mulch percent visual deterioration (PVD) during the summer growing season in open-field and high tunnel production systems, and compared these to mulch mechanical properties at mulch installation (12-30 May), midseason (22 July-9 Aug.), and season end (6-25 Oct.), to determine if the field-based measures reliably predict degradation as revealed by changes in mulch mechanical properties. Four different types of biodegradable mulches [two plastic film mulches marketed as biodegradable (BioAgri and BioTelo); one fully biodegradable paper mulch (WeedGuardPlus); and, one experimental spunbonded plastic mulch designed to biodegrade (SBPLA)] were evaluated against a standard nonbiodegradable polyethylene (PE) mulch where tomato (Solanum lycopersicum L. cv. Celebrity) was planted as the model crop. Each year for the 3 years, PVD increased earlier for WeedGuardPlus than the other mulches in both the high tunnel and open field, and WeedGuardPlus had the greatest PVD in both high tunnels and the open field $(6 \%$ and $48 \%$, respectively). Mechanical strength of WeedGuardPlus also declined by the end of the season both in the high tunnel (up to $46 \%$ reduction) and in the open field (up to $81 \%$ reduction). PVD of BioAgri and BioTelo reached a maximum of $3 \%$ in the high tunnel and $28 \%$ in the open field by the end of the season. Mechanical strength of BioAgri and BioTelo did not change over the course of the season in either the open field or high tunnel, even though the ability of these mulches to elongate or stretch declined $89 \%$ in the open field and $82 \%$ in the high tunnel. SBPLA and PE mulches did not show a change in PVD or mechanical properties in either the high tunnel or the open field. Overall, PVD was three to six times greater by midseason in the open field than in the high tunnels. Although there were significant relationships between visual assessments and various mechanical properties for each mulch except SBPLA, the relationships differed for each mulch when evaluated separately and had coefficients of determination $\left(R^{2}\right)$ below $30 \%$. Furthermore, PVD overestimated mechanical deterioration of BioAgri and BioTelo. Results of this study indicate that mulch visual assessments may reflect general trends in changes in certain mechanical properties of the mulch; however, visual assessment and mechanical properties provide different information on deterioration. Each should be used as needed, but not as a substitute for each other.
PE plastic mulch is used widely in specialty crop production to control weeds, conserve soil moisture, increase crop yields, modify soil temperature, and shorten the time to harvest (Hill et al., 1982; Schonbeck, 1998; Schonbeck and Evanylo, 1998; Shogren, 2000). These benefits provide farmers worldwide with significant horticultural and economic advantages (Takakura and Fang, 2001). However, the widespread use of PE mulch creates removal and disposal costs to growers as well as costs to the environment due to waste plastics being buried in landfills and on farm, or burned. As an alternative, plastic mulches that are biodegradable have been developed. These products first appeared on the market in the 1980s, and may be made from renewable, natural, or sustainable feedstocks (Hayes et al., 2012; Miles et al., 2009). They provide the benefits of PE mulch, such as weed suppression and improved crop yields, and are purported to completely degrade between crop seasons (Cowan et al., 2014; Miles et al., 2012; Minuto et al., 2008; Moreno and Moreno, 2008). Because farmers must bear the annual cost of mulch removal and disposal, estimated at $\approx \$ 250$ per hectare (Shogren and Hochmuth, 2004), the ability to till mulch into the soil following harvest with confidence that biodegradation will occur is an economic incentive (Olsen and Gounder, 2001). Additionally, the environmental benefit of a mulch that degraded completely in soil without producing toxic byproducts would be highly desirable.

Biodegradable plastics typically undergo a two-phase degradation process: disintegration or weathering during use in the field, and biodegradation, which occurs after being incorporated into the soil (Krzan et al., 2006; Kyrikou and Briassoulis, 2007). Moisture, temperature, and light are key factors that impact disintegration, and interactions among these factors may further enhance degradation (Hakkarainen, 2002; Ho et al., 1999; Krzan et al., 2006). Disintegration can lead to decreased molecular weight and increased water solubility of the plastic, which subsequently facilitates biodegradation (Lucas et al., 2008). During biodegradation, biotic processes mineralize the polymer fragments to carbon dioxide, water, and microbial biomass (Lucas et al., 2008). In this study, the word "deterioration" is used to reflect a reduction in the function or visual intactness of the mulch without respect to any particular mode of action or biological process.

Parameters typically measured in the field and laboratory to evaluate deterioration of biodegradable mulch films include reduction in soil coverage, weight loss, and changes in mechanical properties. Measuring the decrease in soil coverage provided by mulch is relatively inexpensive and can be performed in the field without the use of special equipment. Measuring changes in mulch weight requires either large samples, or sensitive laboratoryquality balances, and cannot be reliably performed in the field. Although measuring mulch weight is less subjective than a visual assessment, weight measurements are subject to error because of soiled samples. Measuring changes in mulch mechanical properties, including breaking 
Table 1. Summary of mulch products and their properties used in a study carried out at Mount Vernon, WA, during 2010-12 tomato growing seasons. Adapted from Dharmalingam et al. (2015).

\begin{tabular}{|c|c|c|c|c|c|c|c|}
\hline Mulch & Manufacturer & Feedstock & Color & $\mathrm{M}_{\mathrm{n}}^{\mathrm{z}}(\mathrm{kDa})$ & $\mathrm{Wt}\left(\mathrm{g} \cdot \mathrm{m}^{-2}\right)$ & Thickness $(\mathrm{mm})$ & Fiber diam $(\mu \mathrm{m})$ \\
\hline BioTelo & Dubois Agrinovation; Waterford, ON, Canada & Mater-bi ${ }^{\circledR}$ & Black & 73.1 & 19 & 0.015 & NA \\
\hline WeedGuardPlus & Sunshine Paper Co; Aurora, CO & Cellulose & Brown & $\mathrm{ND}^{\mathrm{x}}$ & 104 & 0.255 & NA \\
\hline SBPLA-10 ${ }^{\mathrm{w}}$ & Hayes et al.; NatureWorks, Blair, NE & PLA & White & 132.1 & 90 & 0.657 & 14.8 \\
\hline SBPLA-12u & Hayes et al.; NatureWorks, Blair, NE & $80 \%$ PLA $/ 20 \%$ PHA & Black & 99.5 & 80 & 0.39 & 18.2 \\
\hline Black plastic & Pliant Corp; Schaumburg, IL & Polyethylene & Black & ND & 24 & 0.025 & NA \\
\hline
\end{tabular}

${ }^{\mathrm{z}}$ Number-averaged molecular weight.

y Fiber diameter is not applicable to films and cellulose mulches.

${ }^{\mathrm{x}} \mathrm{M}_{\mathrm{n}}$ was not determined for cellulose and polyethylene mulches.

wSBPLA-10 was a white, nonwoven experimental fabric.

${ }^{v}$ SBPLA-11 included $1 \%$ to $2 \%$ carbon black, and had reduced molecular weight and fiber diameter compared with SBPLA-10

"The feedstock composition of SBPLA-12 was adjusted to $80 \%$ polylactic acid (PLA) and $20 \%$ polyhydroxyalkanoate (PHA).

force and elongation to break, among others, are objective and accurate, but requires specialized laboratory equipment and climate-controlled facilities. If visual assessment of soil coverage reliably predicts degradation of biodegradable plastic mulches, the need for more expensive and less accessible methods may be obviated, despite the potential for greater accuracy.

To quantify biodegradable mulch deterioration and compare mulch performance in the field, Miles et al. (2012) measured the number of rips, tears, and holes (RTH), as well as the PVD in three distinct climates of the United States. However, the authors found RTH to be an unreliable measure of deterioration due to the coalescence of RTH over time, leading to underestimation of deterioration. Other studies have used similar observations to visually rate or evaluate loss of integrity of biodegradable mulch on the soil surface (Minuto et al., 2008; Moreno and Moreno, 2008; Moreno et al., 2009; Ngouajio and Ernest, 2005; Ngouajio et al., 2008), but none have been adopted as a standard of measurement. In addition, other investigators have evaluated changes in mulch mechanical properties over time to evaluate deterioration (Briassoulis, 2006, 2007; Candido et al., 2006; Cascone et al., 2008; Kijchavengkul et al., 2008; Scarascia-Mugnozza et al., 2006; Tocchetto et al., 2001). Martín-Closas et al. (2007 and 2008) implied that visual observations of biodegradable mulch deterioration were related to changes in mechanical properties, though no statistical comparisons were made between the measures.

Studies that statistically analyze the relationships between visual assessments of mulch deterioration in the field and mechanical properties in the laboratory have not yet

Received for publication 3 Sept. 2015. Accepted for publication $13 \mathrm{Jan} .2016$.

This work was supported by the USDA SCRI grants No. 2009-51181-05897 and No. 2014-51181-22382, and the NIFA Hatch project 1008680.

Mention of a trademark, proprietary product, or vendor does not constitute a guarantee or warranty of the product by the authors, their respective institutions, or ASHS, and does not imply its approval to the exclusion of other products or vendors that also may be suitable.

${ }^{1}$ Corresponding author. E-mail: jeremy.cowan@wsu. edu.

Table 2. Study dates and growing environment characteristics in high tunnels (HT) and open field (OF) tomato plots at Mount Vernon, WA, during 2010-12 Summer growing seasons. Adapted from Cowan et al., (2014).

\begin{tabular}{|c|c|c|c|c|c|c|}
\hline & \multicolumn{2}{|c|}{2010} & \multicolumn{2}{|c|}{2011} & \multicolumn{2}{|c|}{2012} \\
\hline & HT & $\overline{\mathrm{OF}}$ & HT & $\overline{\mathrm{OF}}$ & HT & $\overline{\mathrm{OF}}$ \\
\hline Mulch laying & 25 May & 25 May & 12 May & 24 May & 14 May & 30 May \\
\hline Tomato planting & 27 May & 3 June & 12 May & 31 May & 21 May & 30 May \\
\hline Mulch removal & 18 Oct. & 8 Oct. & 25 Oct. & 25 Oct. & 11 Oct. & 11 Oct. \\
\hline No. of days mulch in place & 146 & 136 & 166 & 154 & 150 & 134 \\
\hline Irrigation [mm (appl. per wk) $]^{\mathrm{z}}$ & \multicolumn{2}{|c|}{$134.1(1), 65.7(2)$} & \multicolumn{2}{|c|}{$61.6(2)$} & \multicolumn{2}{|c|}{$24.8(5), 24.8(4)$} \\
\hline Fertigation (kg N/ha) & 175 & 151 & 179 & 158 & 73 & 64 \\
\hline \multicolumn{7}{|l|}{ Mulch sampling } \\
\hline Initial & 12 May & 24 May & 12 May & 24 May & 14 May & 30 May \\
\hline Midseason & 22 July & 29 July & 27 July & 9 Aug. & 25 July & 7 Aug. \\
\hline Season end & 12 Oct. & 6 Oct. & 25 Oct. & 25 Oct. & 11 Oct. & 11 Oct. \\
\hline
\end{tabular}

${ }^{\mathrm{z}}$ Second set of values in 2010 and 2012 reflects a change in application rate; in 2010, application rate changed on 12 Aug., and in 2012 application rate changed on 5 Aug.

been reported. However, an increased awareness and understanding of such relationships could contribute to more accurate interpretations about visual measures of deterioration. The research reported here builds on the work of Miles et al. (2012), and seeks to determine whether visual assessments of biodegradable mulch intactness during the growing season (independent variable) predict statistically significant changes in mechanical properties (dependent variables). Additionally, the study was designed to contrast mulch deterioration in open-field and high tunnel production environments to expand on potential agricultural settings. Tomato (Solanum lycopersicum cv. Celebrity) was selected as the model crop for this study because it is an important vegetable crop throughout the United States and plastic mulch is a common and important component of tomato production systems (Lamont, 1993).

\section{Materials and Methods}

The field portion of this study was carried out at Washington State University (WSU) Northwestern Washington Research and Extension Center at Mount Vernon, WA. Soil type is a Skagit silt loam and a high water table persists during the growing season (76-91 $\mathrm{cm}$ below the surface) (Klungland and McArthur, 1989; National Resources Conservation Service, 2010). Throughout the study, as well as the 2 years prior, the field site was managed according to the standards for certified organic production set by U.S. Department of Agriculture
National Organic Program. However, the field site was not certified for organic production. The laboratory portion of this study was carried out at the Textiles Laboratory in the Department of Apparel, Merchandizing, Design and Textiles, WSU, Pullman, WA. Environmental data were previously presented in Cowan et al. (2014).

Experimental design. The experimental design was a split-plot design with four replicate blocks; main plots were arranged as a randomized complete block design. The two main plot treatments were high tunnel and open field, and were assigned randomly within each replication and remained fixed throughout this 3-year study (2010-12). The subplots were five mulch treatments that included two plastic films marketed as biodegradable [BioAgri (BioBag USA, Palm Harbor, FL) and BioTelo (Dubois Agrinovation, Waterford, ON, Canada)]; one biodegradable paper [WeedGuardPlus (Sunshine Paper Co, Aurora, CO)]; one biodegradable experimental spun-bond mulch [SBPLA (NatureWorks, Blair, NE)]; and, one black plastic (Pliant Corp, Schaumburg, IL) mulch (PE; control) (Table 1). Feedstock for the experimental SBPLA was obtained from NatureWorks (Blair, NE) and reformulated each year based on study results such that the number appended to the end of the treatment name indicates the formulation year (Dharmalingam et al., 2015). Subplots measured $4.3 \mathrm{~m}$ long and were randomized within each main plot in 2010 . Treatment assignments remained the same in each subplot in 2011 and 2012 to avoid potential cross-treatment contamination. 


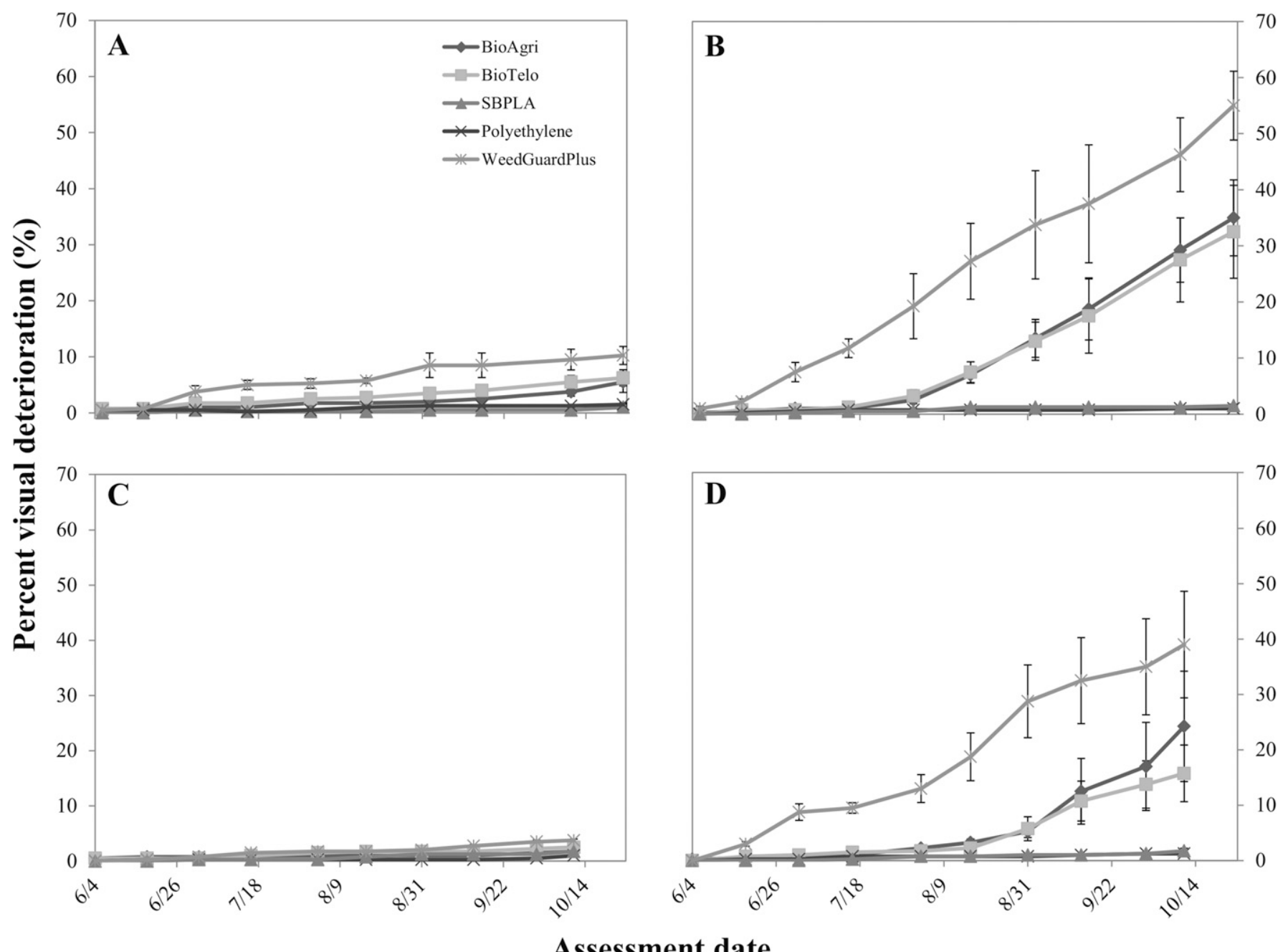

Assessment date

Fig. 1. Percent visual deterioration (PVD) of mulch treatments during (A-B) 2011 and (C-D) 2012 Summer growing seasons in (A, C) high tunnel and (B, D) open field tomato production systems at Mount Vernon, WA (2010 data presented in Miles et al., 2012). Error bars represent the standard error of the mean.

Site preparation. Main plots were separated by a 9-m-wide alley to prevent shading by high tunnels onto adjacent plots. High tunnels (Haygrove Solo, Haygrove Inc., Mount Joy, PA) were $36.6 \mathrm{~m}$ long, $8.4 \mathrm{~m}$ wide, and $2.7 \mathrm{~m}$ high, and were covered with greenhouse plastic (ultraviolet-treated, Tufflite IV, $0.152 \mathrm{~mm}$ thick, 4-year Greenhouse Poly; Horticultural Supply, Sumner, WA). Each main plot had four beds, $0.8 \mathrm{~m}$ wide and spaced $1.85 \mathrm{~m}$ center to center, with one of the center beds assigned randomly to this study. Each year, fertilizer (Par-4, 9N-1.3P5.8K; North Pacific Ag products, Clackamas, OR) was broadcast over the bed centers at the rate of $90 \mathrm{~kg} \mathrm{~N} / \mathrm{ha}$, and incorporated by rototilling. Drip tape (T-Tape 508-8-340 low flow, $1.6 \mathrm{~cm}$ diameter, $0.203 \mathrm{~mm}$ wall thickness, $20.3 \mathrm{~cm}$ emitter spacing; Deere \& Company, Moline, IL) was centered on each bed and laid below the mulches. Mulches were installed by hand each year by rolling the mulch over the surface of the bed and drip tape, and burying the sides in predug furrows along the sides of the bed. Transplant holes were cut by hand $(10 \mathrm{~cm}$ diameter), spaced $0.6 \mathrm{~m}$ apart in the center of each subplot, and tomato cv. Celebrity

Table 3. Area under the mulch deterioration progress curve (AUMDPC) means associated with the production systems and mulch treatments applied to tomato plots at Mount Vernon, WA, during 2010-12 Summer growing seasons. ${ }^{\mathrm{z}}$

\begin{tabular}{lcrrr}
\hline & \multicolumn{4}{c}{ AUMDPC values } \\
\cline { 2 - 5 } & $2010^{\mathrm{y}}$ & $2011^{\mathrm{y}}$ & $2012^{\mathrm{y}}$ & Years combined $^{\mathrm{y}}$ \\
\hline Production system & $140 \mathrm{~b}$ & $357 \mathrm{~b}$ & $133 \mathrm{~b}$ & $210 \mathrm{~b}$ \\
$\quad$ High tunnel & $430 \mathrm{a}$ & $1,367 \mathrm{a}$ & $779 \mathrm{a}$ & $858 \mathrm{a}$ \\
Open field & 0.05 & $<0.0001$ & 0.02 & $<0.0001$ \\
$P$ value & & & & \\
Mulch treatment & $156 \mathrm{~b}$ & $927 \mathrm{~b}$ & $434 \mathrm{~b}$ & $505 \mathrm{~b}$ \\
BioAgri & $178 \mathrm{~b}$ & $966 \mathrm{~b}$ & $402 \mathrm{~b}$ & $515 \mathrm{~b}$ \\
BioTelo & $977 \mathrm{a}$ & $2,220 \mathrm{a}$ & $1,298 \mathrm{a}$ & $1,498 \mathrm{a}$ \\
WeedGuardPlus & $41 \mathrm{c}$ & $85 \mathrm{~d}$ & $83 \mathrm{c}$ & $70 \mathrm{c}$ \\
SBPLA-10/11/12 & $74 \mathrm{c}$ & $112 \mathrm{c}$ & $64 \mathrm{c}$ & $84 \mathrm{c}$ \\
Polyethylene & $<0.0001$ & $<0.0001$ & $<0.0001$ & $<0.0001$ \\
$P$ value & &
\end{tabular}

${ }^{2}$ Higher AUMDPC values indicate greater mulch deterioration. Means within a column followed by the same letter are not significantly different $(P>0.05)$ as determined by Fisher's protected least significant difference (LSD) test.

${ }^{y}$ No transformation satisfied the assumptions of normality for analysis of variance; therefore, data were nonparametrically transformed, and untransformed means reported.

(Territorial Seed Company, Cottage Grove, OR) were transplanted 6 to 7 weeks after seeding in a greenhouse. Dates for mulch installation and removal, tomato planting, and mulch sampling as well as rates for irrigation and fertigation each year are summarized in Table 2 .
Visual assessments. Mulch PVD was assessed in each treatment subplot twice each month for three months each year, from 16 June to 29 Sept. 2010, 6 June to 24 Oct. 2011, and 4 June to 11 Oct. 2012. Additional PVD assessments were performed concurrent with mulch sample extractions at midseason and 
season end each year (Table 2) to compare with measures of mulch mechanical properties. Mulches were assessed over the full width of the bed $(0.8 \mathrm{~m})$ between the fourth and seventh plant $(1.8 \mathrm{~m})$ in each subplot. PVD was estimated as the percent of soil exposed within the evaluated area such that $0 \%=$ intact mulch, and $100 \%=$ completely deteriorated mulch. PVD was measured in $1 \%$ increments from $0 \%$ to $20 \%$, and in $5 \%$ increments thereafter. The aggregate area under the mulch deterioration progress curve (AUMDPC) was calculated from semimonthly PVD values according to the following formula:

$$
\begin{aligned}
\text { AUMDPC } & =\sum_{n=1}^{n}\left(t_{n}-t_{n-1}\right) \\
& \times\left(\begin{array}{l}
\frac{\left|\mathrm{PVD}_{n}-\mathrm{PVD}_{n-1}\right|}{2} \\
+\min \left(\mathrm{PVD}_{n}, \mathrm{PVD}_{n-1}\right)
\end{array}\right)
\end{aligned}
$$

where $t=$ number of days after mulch installation at measurement $n=0$.

Mulch sampling and mechanical properties assessment. Mulch samples were collected three times during each growing season, at installation, midseason, and season end (Table 2). These sampling times corresponded to transplanting, $50 \%$ flowering, and final harvest, respectively, for the tomato crop. At midseason (70 d after laying, on average), mulch samples were taken from the full width of the bed $(0.8 \mathrm{~m})$ between the first and second plants $(0.6 \mathrm{~m})$ in each subplot. At the end of the season (145 d after laying, on average), samples were collected from the full width of the bed between the second and third plants in each subplot. This study did not evaluate deterioration of the buried (tucked) edges of the mulches. The initial mulch sample did not require cleaning because it was taken directly from the roll at time of laying, whereas the second and third mulch samples were cleaned by hand to remove soil (soil can interfere with laboratory equipment used to measure mechanical properties). For cleaning, plastic film mulches were showered gently with water and lightly wiped carefully with a cellulose sponge. WeedGuardPlus was brushed gently with a soft-bristled brush to remove debris to minimize damage to the mulch. SBPLA was briefly $(<30$ s) submerged in water and agitated by hand to remove soil from the fibers. All cleaned mulch samples were air-dried for 1 to $2 \mathrm{~d}$ before transporting to the Textiles Laboratory (WSU, Pullman, WA).

For each mulch sample, eight subsamples were collected, with three collected in the machine direction (parallel to the length of the roll) and five collected in the transverse direction (perpendicular to the length of the roll). Each subsample was $2.5 \mathrm{~cm}$ wide and $15.2 \mathrm{~cm}$ long, and cut by pressing cast dies into mulch samples on a smooth surface using a hydraulic press. This process ensured uniformity of subsamples and minimized stretching mulch films along cut edges. Subsamples were cut according to a predefined template that was randomized to eliminate sampling bias. Subsamples were held under laboratory conditions $\left(65 \%\right.$ relative humidity and $\left.21^{\circ} \mathrm{C}\right)$ for at least $48 \mathrm{~h}$ before testing. All subsamples were tested for breaking force (BF, measured in Newtons, N) and percent elongation (El) at breaking in both the machine (M) and the transverse $(\mathrm{T})$ directions using a universal testing machine (Instron 5565A; Instron, Norwood, MA) in accordance with ASTM D5035-06 (ASTM, 2006). Measurements collected at midseason and season end were compared with the same properties measured at mulch installation at the beginning of the season, using percentage change ratios. At the end of the season in 2012, the deterioration of BioAgri, BioTelo, and WeedGuardPlus caused too few subsamples to be available in the transverse direction, therefore, no mulches were tested at that sampling time.

Comparing measures of deterioration. Visual assessment parameters included PVD, the percent of initial PVD (PVD-PD, equal to $100 \%$ - PVD), AUMDPC, and the $\log _{10}$ transformation of each measure (PVD-L10, PVD-PD-L10, and AUMDPC-L10, respectively). Mechanical property parameters included breaking force in the machine and transverse directions (BF-M and BF-T, respectively), elongation at break in the machine and transverse directions (El-M and El-T, respectively), and the percent of the initial

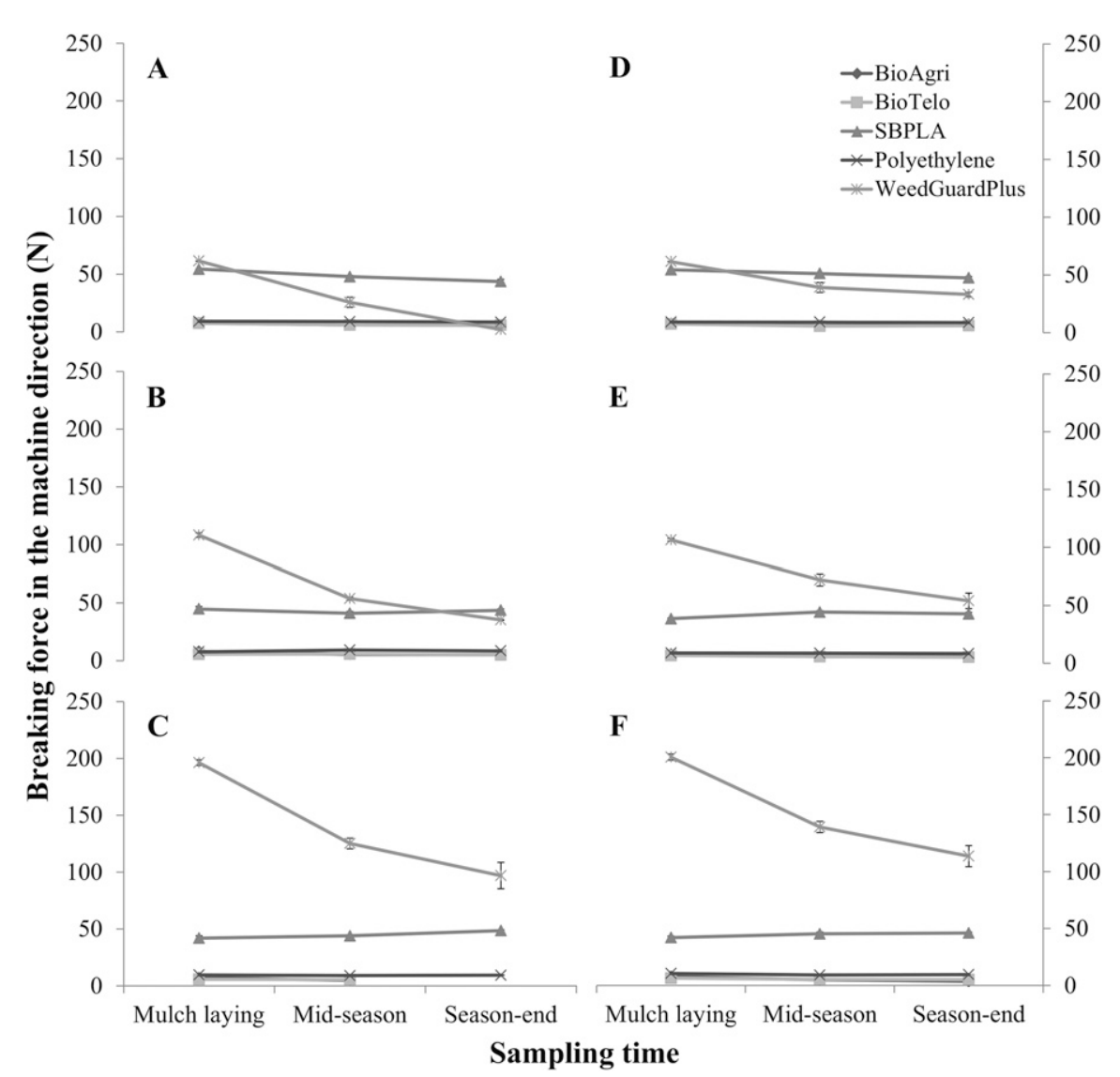

Fig. 2. Breaking force $(\mathrm{N})$ in the machine direction (BF-M) of five mulch treatments (BioAgri, BioTelo, SBPLA, polyethylene, and WeedGuardPlus) in (A-C) open field and (D-F) high tunnel tomato production systems at Mount Vernon, WA, during (A and D) 2010, (B and E) 2011, and (C and F) 2012 Summer growing seasons. Error bars represent the standard error of the mean. In 2012, BioAgri and BioTelo were not sufficiently intact in the open field by the end of the season to measure BF-M for these mulch products.

measure of each parameter (BF-M-PD, BF-TPD, El-M-PD, and El-T-PD, respectively), where BF-M-PD at midseason equals BF-M at midseason divided by the average BF-M at initial mulch sampling that year. The relationships between visual assessments and mechanical properties were evaluated using the REG macro (Saxton, 2010) in SAS. Regression analysis was used rather than correlation to assess predictability of mechanical properties from visual assessments across various conditions. The relationship with the highest coefficient of determination $\left(R^{2}\right)$ was identified and subjected to dummy regression analysis to determine whether year, sampling time, production system, mulch treatment, or the interactions among those factors influenced the relationship at alpha $=0.05$. When a significant effect was identified, separate $R^{2}$ values were compared across each level of the confounding factor(s).

Statistical analyses. Analysis of variance for all data was performed using PROC MIXED (SAS Institute, Cary, NC). The Mixed Model Analysis of Variance macro (Saxton, 2010) was used to run the analyses and the Kenward and Roger (1997) method was used to determine denominator $\mathrm{df}$ for $\mathrm{F}$ tests. Fisher's least significant difference test was used to compare treatment means at a significance level of 0.05 . Treatments were analyzed

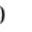
. . 
separately when significant interactions were detected between main effects (year, sampling time, production system, and mulch). Some data were transformed before analysis to satisfy the assumptions of normality and homogeneity of variance. Appropriate transformations were selected using the range method described by Kirk (1982). If data transformation failed to satisfy assumptions of normality and homogeneity of variance, nonparametric transformation of the data was applied using PROC RANK in SAS. Untransformed means are presented in the results, but all statistical analyses used transformed data as needed to satisfy model assumptions.

\section{Results}

Visual assessments. PVD differed by year and sampling time $(P<0.0001$ for both), therefore, results are presented separately. PVD was three to six times greater by midseason in the open field than in high tunnels in 2010 (data previously published in Miles et al., 2012), 2011, and 2012 ( $P \leq$ $0.01, P<0.003$, and $P<0.01$, respectively). In each year, PVD differed by mulch treatment at every sampling time $(P<0.05$; Fig. 1). Significant interactions were detected between production system and mulch treatment in all 3 years $(P \leq 0.05)$. Early in each season, PVD for WeedGuardPlus was greater in the open field and less in high tunnels, relative to BioAgri and BioTelo. At midseason in 2010 and through the latter half of 2011, PVD for SBPLA was greater in the open field and lower in high tunnels relative to PE. Late in 2010 and 2012, PVD of BioAgri was greater in the open field and lower in high tunnels relative to BioTelo. Across all 3 years, WeedGuardPlus had the highest PVD in both the high tunnel and the open field as compared with the other mulches in this study. Each year, increases in PVD for WeedGuardPlus occurred earlier in the season than for the other mulches, and on average, reached a maximum of $6 \%$ in the high tunnel and $48 \%$ in the open field by the end of the season. PVD for BioAgri and BioTelo (both made with the same feedstock Mater-Bi) were similar all 3 years, and on average, reached a maximum of $3 \%$ in the high tunnel and $28 \%$ in the open field by the end of the season. PVD for SBPLA was equivalent to $\mathrm{PE}$ and showed negligible change across all three years, similar to findings during simulated weathering (Hablot et al., 2014). Overall, PVD was three to six times higher by midseason in the open field than in the high tunnels $(P \leq 0.01)$.

AUMDPC differed by year $(P<0.0001)$, therefore, results were analyzed separately (Table 3). In 2011, an interaction between mulch treatment and production system was detected $(P=0.01)$ due to PE having a greater AUMDPC value in high tunnels than in the open field, contrary to the trend of all the other mulch treatments. However, AUMDPC of PE in high tunnels and the open field did not differ statistically and PVD at season end was only $1.5 \%$ and $1.0 \%$, respectively, indicating that deterioration was negligible. Averaged over 3 years, AUMDPC was four times greater in the open field than in the high tunnel. WeedGuardPlus had the greatest AUMDPC in all 3 years, and was three times greater than BioAgri and BioTelo, and $\approx 20$ times greater than SBPLA and PE. Overall, average AUMDPC of BioAgri and BioTelo was seven times greater than SBPLA and PE.

Mechanical properties. Significant interactions among year and sampling time $(P<$ and elongation in the machine and transverse directions, therefore, results are presented separately (Figs. 2-5). Significant differences in BF-M were detected due to production system at midseason in $2011(P<0.0001)$, and at season end in 2010 and $2011(P=$ 0.0003 and $P=0.02$, respectively) (Fig. 2). Significant differences in BF-M were detected due to mulch treatment at mulch installation in $2011(P<0.0001)$, at midseason in $2012(P<0.0001)$, and at season end in all 3 years $(P<0.0001$ all years $)$. Significant interactions were detected between production system and mulch effects. At mulch installation in 2011, BioAgri had lower BF-M in the open field relative to BioTelo in the open field and PE in high tunnels $(P=0.0003)$; at mulch installation in 2012,

Fig. 3. Breaking force $(\mathrm{N})$ in the transverse direction (BF-T) of five mulch treatments (BioAgri, BioTelo, SBPLA, polyethylene, and WeedGuardPlus) in (A-C) open field and (D-F) high tunnel tomato production systems at Mount Vernon, WA during (A and D) 2010, (B and E) 2011, and (C and F) 2012 Summer growing seasons. Error bars represent the standard error of the mean. In 2012, WeedGuardPlus was not sufficiently intact by midseason, and BioAgri and BioTelo were not sufficiently intact in the open field by season end, to measure BF-T for these mulch products. Therefore, no BF-T measurements were performed at season end in 2012 .

when BioAgri had lower BF-M in the open field relative to $P E$ in high tunnels $(P<0.0001)$; and, at season end in 2010 when BioTelo in high tunnels had lower BF-M relative to BioAgri in the open field, and WeedGuardPlus in the open field had lower BF-M relative to PE in high tunnels $(P<0.0001)$.

Significant differences in BF-T were detected due to production system at mulch installation in 2011 and $2012(P=0.03$ and $P=0.008$, respectively) (Fig. 3). Significant differences in BF-T were also detected due to mulch treatment at mulch installation in 2011 and $2012(P<0.0001$ for both years $)$, at midseason all three years $(P<0.0001$ for all 3 years), and at season end in 2010 and 2011 $(P<0.0001$ for both years). Significant tion installation in 2011, BioAgri had lower BF-T in the open field relative to BioTelo in the open field and PE in high tunnels $(P=0.003)$; at mulch installation in 2012, though an interaction was detected, the relative performance of each mulch was the same in high tunnels and the open field $(P=0.0001)$; at midseason in 2011, BioAgri in the open field had lower BF-T than in high tunnels relative to BioTelo $(P=0.04)$; and, at season end in 2010 , WeedGuardPlus in the open field had $0.05)$ were detected for mulch breaking force

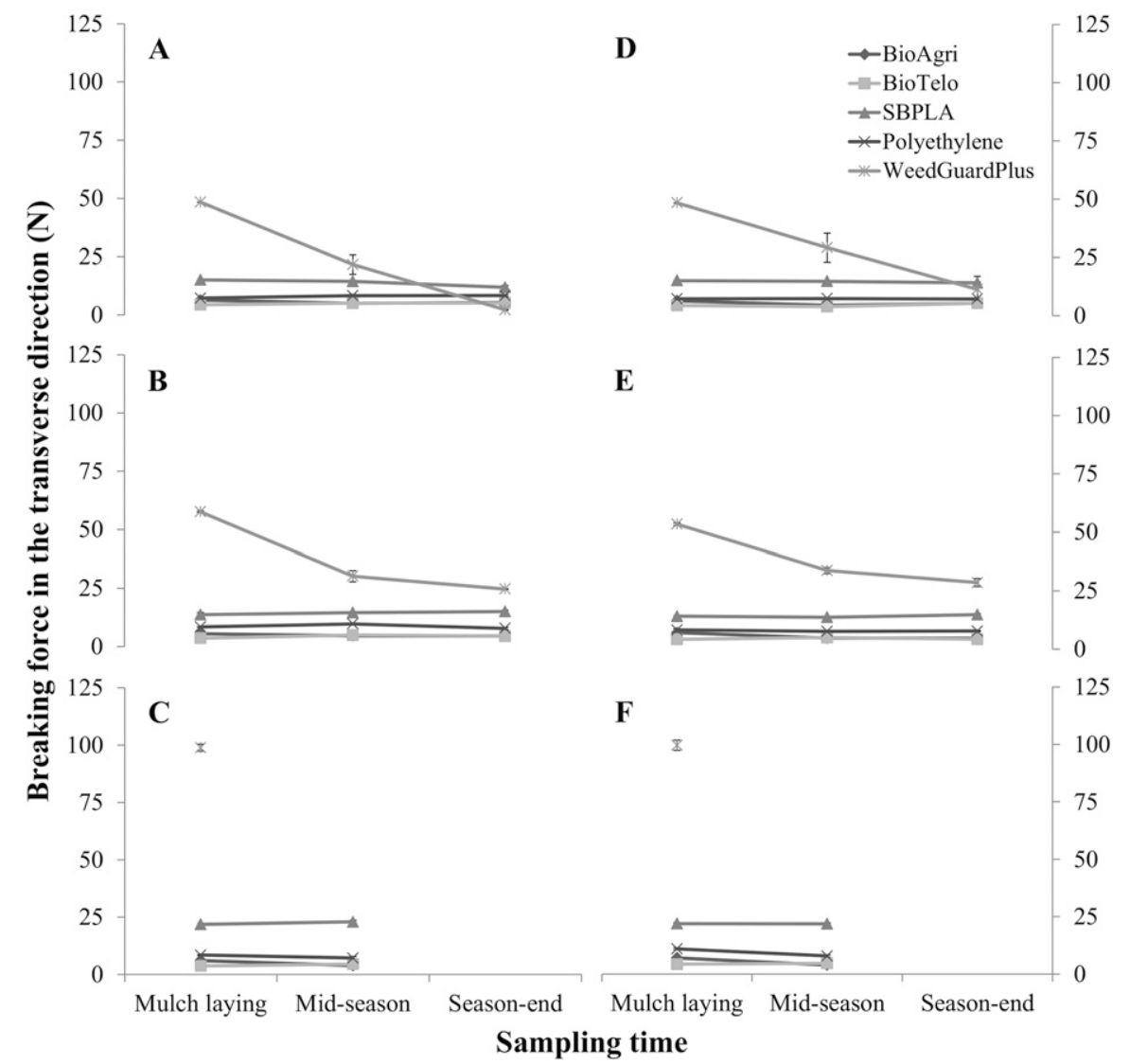




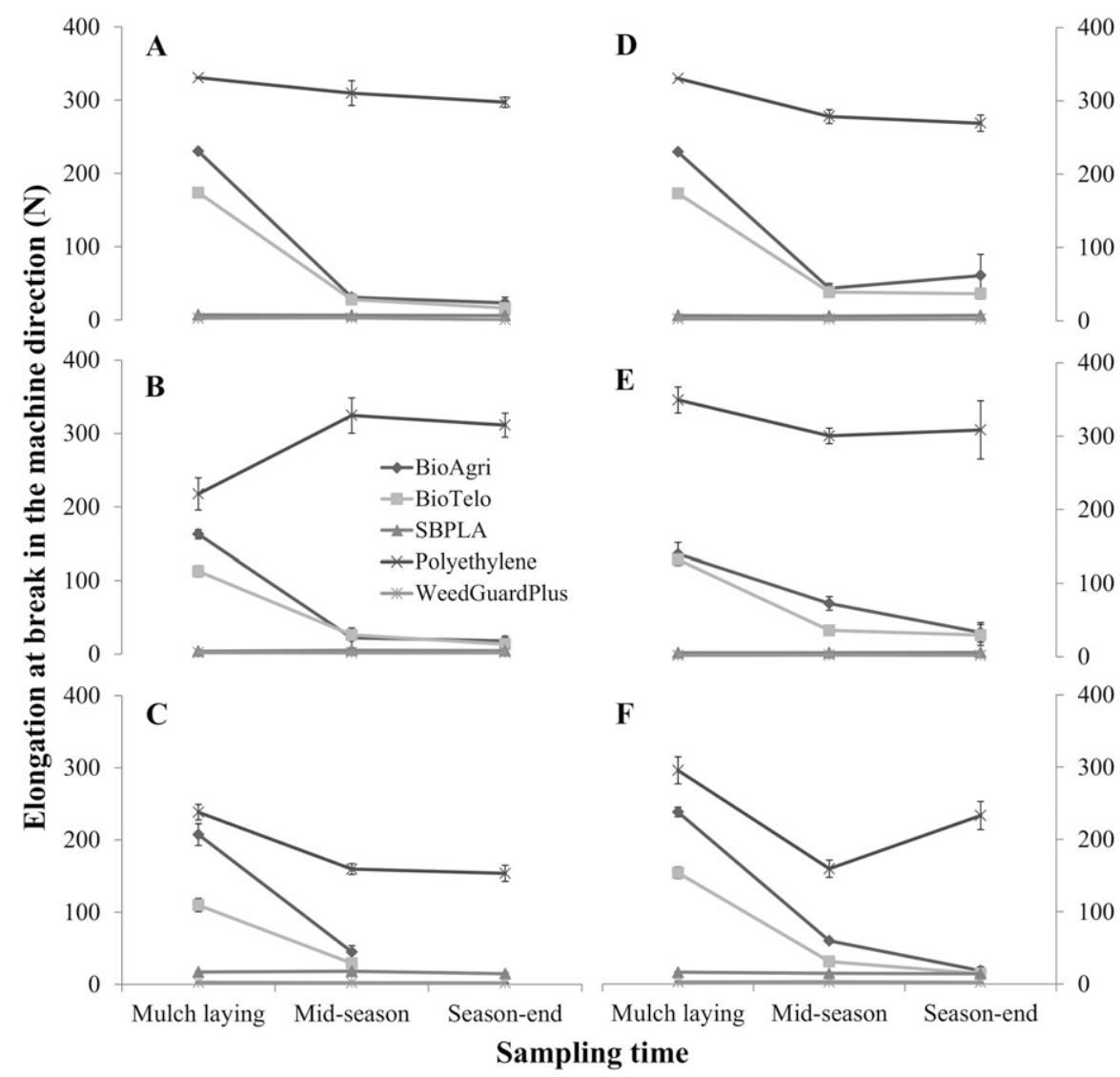

Fig. 4. Elongation at break (\%) in the machine direction (BF-M) of five mulch treatments (BioAgri, BioTelo, SBPLA, polyethylene, and WeedGuardPlus) in (A-C) open field and (D-F) high tunnel tomato production systems at Mount Vernon, WA, during (A and D) 2010, (B and E) 2011, and (C and F) 2012 Summer growing seasons. Error bars represent the standard error of the mean. In 2012, BioAgri and BioTelo were not sufficiently intact in the open field by the end of the season to measure $\mathrm{BF}-\mathrm{M}$ for these mulch products.

lower BF-T than in high tunnels relative to all other mulch treatments, and BioAgri and BioTelo in the open field had lower BF-T than in high tunnels relative to PE $(P=0.04)$.

Significant differences in El-M were detected due to production system at midseason in 2011 and 2012 ( $P<0.0001$ for both years $)$ and at season end in $2010(P=0.0003)$ (Fig. 4). Significant differences in El-M were also detected due to mulch treatment at mulch installation in 2011 and $2012(P<$ 0.0001 for both years), at midseason in 2010 and 2012 ( $P<0.0001$ both years $)$, and at season end all 3 years $(P<0.0001$ for all years). Significant interactions were detected between production system and mulch effects. At mulch installation in 2011, BioTelo had lower El-M in high tunnels relative to BioAgri in the open field $(P<0.0001)$. At season end in 2010 and at midseason in 2012 $(P=0.04$ and $P=0.01$, respectively) significant interactions were detected, however, the relative performance of each mulch was the same in high tunnels and the open field at both sampling times.

No significant differences in El-T were detected due to production system (Fig. 5). Significant differences in El-T were detected due to mulch treatment at mulch installation in 2011 and $2012(P=0.0008$ and $P<0.0001$, respectively), at midseason in all 3 years $(P<0.0001$ for all 3 years $)$, and at season end in 2010 and $2011(P<0.0001$ for both years). Significant interactions were detected between production system and mulch effects. At midseason in 2010, though significant interactions were detected, the relative performance of each mulch was the same in high tunnels and the open field $(P=$ 0.04 ); at midseason in 2011, BioAgri in the open field had lower El-T than in high tunnels relative to BioTelo $(P=0.01)$; and, at season end in 2010, though significant interactions were detected, the relative performance of each mulch was the same in high tunnels and the open field $(P=0.001)$.

Evaluating relationships between visual assessments and mechanical properties. When data were analyzed together, the relationship between PVD-L10 and BF-M-PD had the highest $R^{2}\left(R^{2}=0.41, P<0.0001\right)$ among all of the possible relationships (Table 4; Fig. 6A). Dummy regression of PVD-L10 and BF-M-PD revealed that the relationship was influenced significantly by the combined effects of year, production system, and mulch $(P=0.04)$.

A summary of the relationships between visual assessments and mulch mechanical properties when analyzed separately by year (Fig. 6B), sampling time (Fig. 6C), production system (Fig. 6D), and mulch (Fig. 6E) is presented in Table 4 . The relationship between PVD-L10 and BF-M-PD was the strongest relationship in 2011, at every sampling time individually, in both the open field and high tunnel, and when averaged across each factor except mulch. Dummy regressions performed for the relationship between PVD-L10 and BF-M-PD for each analysis except mulch indicated that when analyzed by year, the combined effects of sampling time and production system in 2011 was significant $(P=0.04)$, but when analyzed by sampling time and production system separately, no outside influences were detected.

When analyzed by mulch (Fig. 7), no relationship was consistently strong for any combination of mulches except the relationship between PVD-L10 and El-M for BioAgri and BioTelo $(P=0.03$ and 0.002 , respectively). Dummy regressions were performed for the strongest relationship when averaged across mulches and for each individual mulch. The relationship between AUMDPC and El-T was influenced significantly by year and production system in the SBPLA treatment $(P=$ 0.03 and $P=0.02$, respectively). The relationship between PVD-L10 and El-M for BioAgri was influenced significantly by the combined effects of year and production system $(P=0.01)$. The relationships between PVD-L10 and El-M for BioTelo, PVD and El-T for WeedGuardPlus, and AUMDPC-L10 and El-T-PD for PE demonstrated no significant outside influences $(P>0.05)$. Except for WeedGuardPlus $(P=$ $0.0001)$, the relationship between PVD-L10 and BF-M-PD was not statistically significant when data were analyzed by mulch.

Regression analysis of each relationship was performed separately by each independent variable to confirm that relationships among visual assessments and mechanical properties for each mulch were consistent over each year, sampling time, and production system. $R^{2}$ values for each relationship were averaged by factor. When data for BioAgri were analyzed by year, the relationships between AUMDPC and El-M and AUMDPC and El-M-PD had the highest average $R^{2}\left(R^{2}=0.18\right.$ for both). However, both relationships were statistically significant only in $2012(P=0.03)$. When analyzed by sampling time, the relationship between AUMDPC-L10 and BF-T for BioAgri had the highest average $R^{2}(0.31)$, but the relationship was only statistically significant at final harvest $(P=0.0004)$. When analyzed by production system, the relationship between AUMDPC-L10 and El-M for BioAgri had the highest average $R^{2}(0.09)$, though the relationship was not statistically significant in either production system $(P>0.05)$.

When data for BioTelo were analyzed by year, the relationships between PVD-L10 and El-M, and PVD-L10 and El-M-PD had the highest average $R^{2}$ values ( 0.35 for both), and both relationships were statistically significant in 2011 and $2012(P=0.02$ and $P=0.01$, respectively). When analyzed by sampling time, the relationship between AUMDPCL10 and El-T-PD for BioTelo had the highest average $R^{2}(0.30)$, but was only statistically significant at final harvest $(P=0.001)$. When 


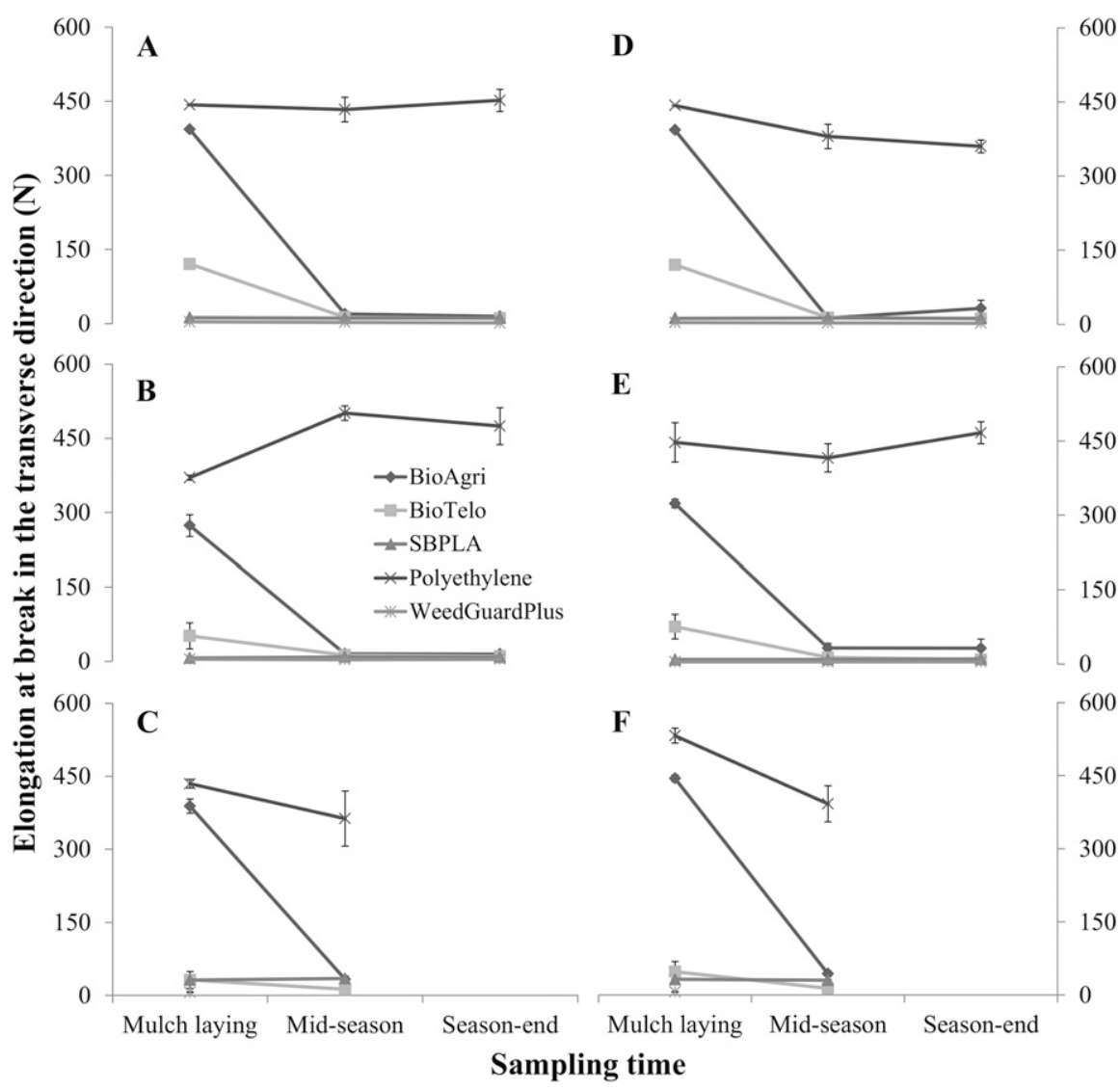

Fig. 5. Elongation at break (\%) in the transverse direction (BF-T) of five mulch treatments (BioAgri, BioTelo, SBPLA, polyethylene, and WeedGuardPlus) in (A-C) open field and (D-F) high tunnel tomato production systems at Mount Vernon, WA, during (A and D) 2010, (B and E) 2011, and (C and F) 2012 Summer growing seasons. Error bars represent the standard error of the mean. In 2012, WeedGuardPlus was not sufficiently intact by midseason, and BioAgri and BioTelo were not sufficiently intact in the open field by the end of the season to measure BF-T for these mulch products. Therefore, no BF-T measurements were performed at season end in 2012. analyzed by production system, the relationship between PVD-L10 and El-M for BioTelo had the highest average $R^{2}(0.27)$, though, the relationship was only statistically significant in the open field $(P=0.0008)$.

When data for WeedGuardPlus were analyzed by year, the relationships between AUMDPC and BF-M, and AUMDPC and BF-M-PD had the highest average $R^{2}$ values (0.45 for both). Both relationships were statistically significant in 2010 and 2011 ( $P<0.0001$ and $P=0.01$, respectively). When analyzed by sampling time, the relationships between PVD and El-T, PVD and El-T-PD, PVD-PD and El-T, and PVD-PD and El-T-PD for WeedGuardPlus had the highest average $R^{2}(0.30)$, but these relationships were statistically significant only at final harvest $(P=$ 0.05 for all four). When analyzed by production system, the relationships between PVD and El-T, PVD and El-T-PD, PVD-PD and El-T, and PVD-PD and El-T-PD for WeedGuardPlus had the highest average $R^{2}$ ( 0.39 for all four). However, none of these relationships were statistically significant in either production system $(P>0.05)$.

When data for PE were analyzed by year, the relationships between AUMDPC and BF-T, and AUMDPC and BF-T-PD had the highest average $R^{2}$ values ( 0.19 for both); however, neither relationship was statistically significant in any year $(P>0.05)$. When analyzed by sampling time, the relationship between AUMDPC and El-M-PD for PE had the highest average $R^{2}(0.17)$, but it was statistically significant only at final harvest $(P=0.01)$. When analyzed by production system, the relationship between AUMDPCL10 and El-T-PD for PE had the highest average $R^{2}(0.20)$, though, the relationship

Table 4. Summary of overall regression analysis and analyses by main effects for the strongest linear relationships found among visual assessments of mulch deterioration including: percent visual deterioration (PVD), the percent of initial PVD (PVD - PD), area under the mulch deterioration progress curve (AUMDPC), and the $\log _{10}$ of each measure (appended with-L10) and mulch mechanical property including: breaking force (BF) and elongation at break (El) in the machine $(-\mathrm{M})$ and transverse $(-\mathrm{T})$ directions, and the percent of the initial value of each parameter $(-\mathrm{PD})$ measured at midseason and season end for mulches at Mount Vernon, WA, during tomato growing seasons, 2010-12.

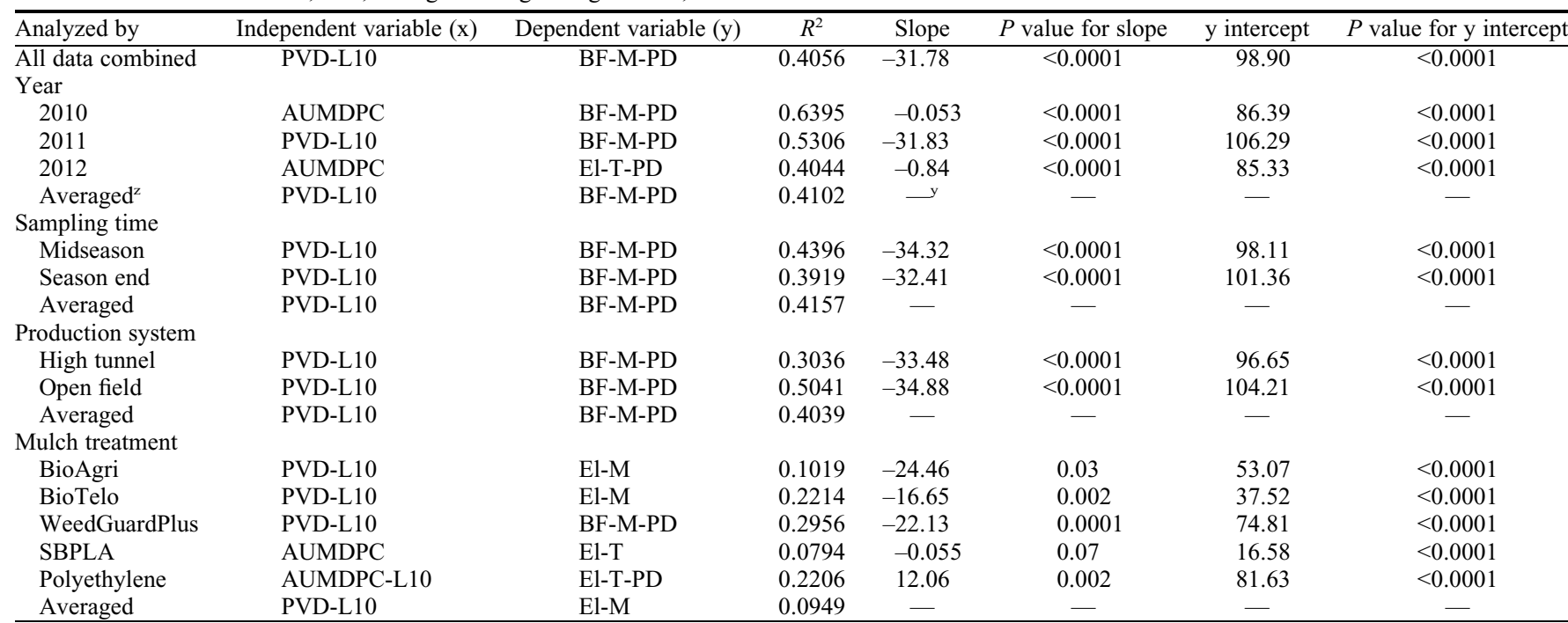

${ }^{2}$ The value of $R^{2}$ for each relationship was calculated for each level and averaged by main effect. The highest average $R^{2}$ and associated relationship is reported for each main effect.

y" _." indicates that the relationship or value is not applicable. 

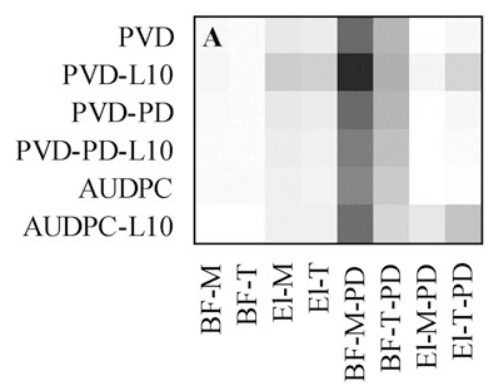

$R^{2} \quad 0.48$
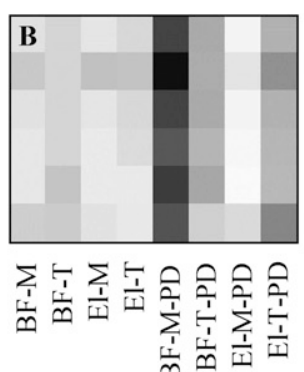

0.36
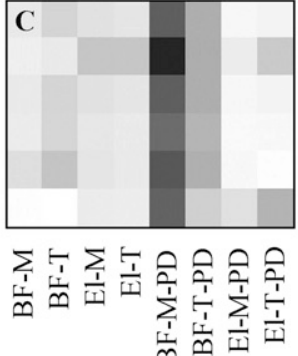

0.24
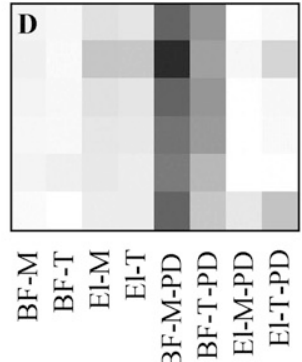

0.12

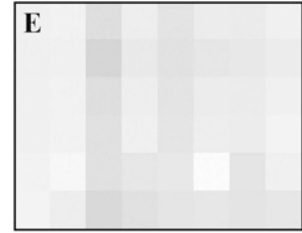

$\sum \varphi_{1}$

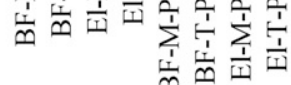

0

Fig. 6. Heat maps indicate the average coefficient of determination $\left(R^{2}\right)$, where darker regions indicate higher average $R^{2}$ values, for relationships between visual assessments of mulch deterioration and mulch mechanical properties. Visual assessment parameters include percent visual deterioration (PVD), percent of initial PVD (PVD-PD, equal to 100 - PVD), and the area under the mulch deterioration progress curve (AUMDPC) with $\log _{10}$ transformations (L10). Mulch mechanical properties include breaking force $(\mathrm{BF})$ and elongation at break $(\mathrm{El})$ in the machine $(\mathrm{M})$ and transverse $(\mathrm{T})$ directions. The percent of initial mulch mechanical properties (PD) are also indicated. Measurements were taken at mulch installation (these "initial measures" were used for comparison with subsequent sampling times, and not included in regression analyses), at midseason, and at the end of the season. Maps represent the average $R^{2}$ of (A) all data combined, and when analyzed separately by (B) year, (C) sampling time, (D) production system, and (E) mulch.
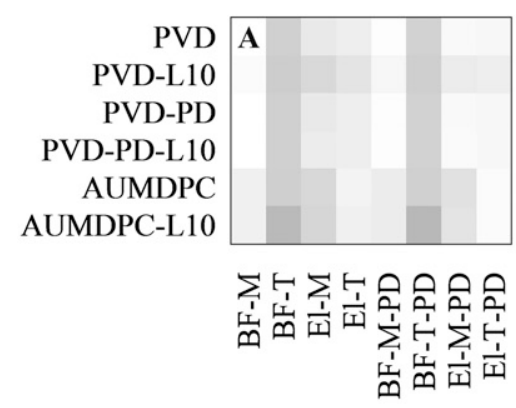

$R^{2}$
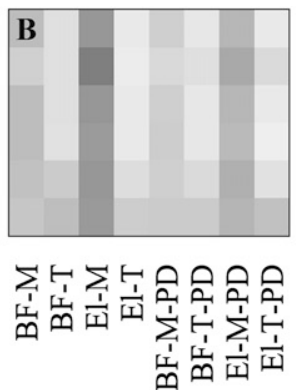

0.36
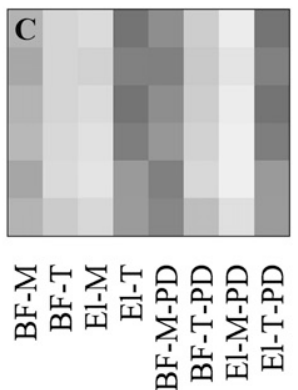

0.24
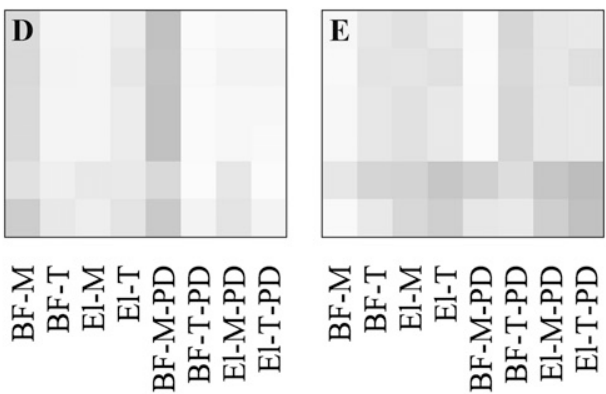

0.12
0

Legend

Fig. 7. Heat maps indicate the average coefficient of determination $\left(R^{2}\right)$, where darker regions indicate higher average $R^{2}$ values, across mulch treatments for relationships between visual assessments of mulch deterioration and mulch mechanical properties. Visual assessment parameters include percent visual deterioration (PVD), the percent of initial PVD (PVD-PD, equal to 100 - PVD), and the area under the mulch deterioration progress curve (AUMDPC) with $\log _{10}$ transformations (L10). Mulch mechanical properties include breaking force (BF) and elongation at break (El) in the machine (M) and transverse (T) directions. The percent of initial mulch mechanical properties (PD) are also included. Measurements were taken at mulch installation (these "initial measures" were used for comparison with subsequent sampling times, and not included in regression analyses), midseason, and season end. Mulch samples were collected from a tomato field experiment performed in Washington State and results are averaged across years, sampling times, and production systems (high tunnel and open field). Maps represent (A) BioAgri, (B) BioTelo, (C) WeedGuardPlus, (D) SBPLA, and (E) polyethylene.

was only statistically significant in high tunnels $(P=0.02)$.

The average $R^{2}$ values for each of the relationships, analyzed by mulch, and each interaction between mulch and year, sampling time, and production system, were calculated (Fig. 7). For BioAgri, the relationship with the highest average $R^{2}(0.20)$ was AUMDPC-L10 and BF-T, but the relationship was not statistically significant $(P=0.39)$. For BioTelo, the relationship between PVD-L10 and El-M had the highest average $R^{2}(0.27)$ and was statistically significant $(P=0.002)$. Furthermore, dummy regression of the relationship between PVD-L10 and El-M for BioTelo indicated no significant influences due to year, sampling time, or production system. For WeedGuardPlus, the relationship between AUMDPC and BFM-PD had the highest average $R^{2}(0.29)$, and was statistically significant $(P=0.003)$. Dummy regression of the relationship between AUMDPC and BF-M-PD for WeedGuardPlus revealed significant influences $(P<0.05)$ due to every test effect except the combined effects of year and sampling time, and of year, sampling time, and production system. For SBPLA, the relationship with the highest average $R^{2}(0.17)$ was PVD-L10 and BF-M-PD, but the relationship was not statistically significant $(P=0.18)$. In fact, no relationship between visual assessments and mechanical properties was statistically significant for SBPLA. For PE, the relationship with the highest average $R^{2}(0.17)$ was AUMDPC and BF-T-PD, but the relationship was not statistically significant $(P=$ 0.39 ) either.

\section{Discussion}

Deterioration of WeedGuardPlus, BioAgri, and BioTelo, as measured by PVD and AUMDPC, occurred more rapidly in the open field than in high tunnels, which provide protected environments. At Mount Vernon, where average maximum temperature was
$23.8{ }^{\circ} \mathrm{C}$ in high tunnels and $21.1{ }^{\circ} \mathrm{C}$ in the open field, the slightly higher temperatures in the high tunnel did not result in greater mulch deterioration relative to the open field. Rather, increased moisture from precipitation, higher relative humidity, increased light intensity, and mechanical forces due to wind, or a combination of these factors, likely led to greater deterioration in the open field. Briassoulis (2007) reported that while temperature and moisture had no significant effect on mulch deterioration, high doses of ultraviolet radiation affected mechanical properties of Mater- $\mathrm{Bi}^{\circledR}$ based mulch films (both BioAgri and BioTelo mulches contain Mater- $\left.\mathrm{Bi}^{\circledR}\right)$.

Each year over the course of the tomato growing season, longitudinal cracks formed in both BioAgri and BioTelo near the center of the bed where irrigation water was most abundant in the soil, and these cracks developed into long splits, which extended down the length of the bed. As the mulch split, it creased and bunched along the edge of the 
split, exposing underlying soil thus leading to higher PVD ratings. As such, PVD likely overestimates deterioration of mulch films, which form longitudinal cracks. Along the side of the bed, where the mulch was buried in the soil, no extraordinary deterioration was noted for BioAgri or BioTelo. In contrast, deterioration of WeedGuardPlus occurred first at the edge of the bed, where the mulch was buried in the soil, then at the center of the bed, where irrigation water was most abundant in the soil. SBPLA and PE did not develop any splits or tears, or exhibit any significant visual evidence of deterioration or degradation throughout this study. In-season decreases in breaking force for paper mulch (Cascone et al., 2008) and decreases in breaking force and elongation at break for biodegradable plastic films as noted in this study are consistent with the findings of other studies in the open field (Blick et al., 2010; Briassoulis, 2007; Kijchavengkul et al., 2008; Scarascia-Mugnozza et al., 2006; Tocchetto et al., 2001).

Regression analysis, combining all of the mulch treatments evaluated in this study, showed that the PVD-L10 increased as the BF-M-PD decreased. Although statistically significant relationships were found between visual assessments and mechanical properties for each mulch treatment except SBPLA, the relationships were generally weak. In two studies that reported measuring mechanical properties more than three times during a growing season, $\mathrm{El}$ and $\mathrm{BF}$ decreased over time, but high variability was noted early in the season which could be attributed to physicochemical changes in the biodegradable films (Briassoulis, 2006; Tocchetto et al., 2001). Because the mechanical properties of mulch depend primarily on chemical composition and conditions of in-field use (Briassoulis, 2004), it is reasonable to expect differences in degradation mechanisms across mulch products, and it appears likely that no relationship will apply consistently across mulch products due to the disparate physicochemical properties of the various formulations.

In conclusion, visual assessments and measures of mechanical properties are tools that can be used to evaluate mulch functionality and deterioration over time. Visual assessments quantify mulch intactness, reflecting the functionality of the material as mulch, and may be influenced by mechanical properties. Mulch intactness may also be influenced by macroscale conditions, such as wind-caused tearing and bunching, which may or may not affect some or all mechanical properties. Furthermore, PVD likely overestimates deterioration of mulch films whenever longitudinal cracks form. Although visual assessments may help predict general trends in changes in mechanical properties, it is important to recognize that visual assessments quantify the function of the material as mulch. In contrast, the mechanical properties reflect the inherent condition and functionality of the material itself. Breaking force and elongation at break measure physical properties of mulch (i.e., resistance to breakage) independent of the effect on mulching ability. Variations in mechanical properties at different stages of deterioration may distort relationships between visual assessments and mechanical properties. Because the physical and chemical properties of mulch materials differ, degradation of each mulch product should be evaluated separately. Given the lack of consistent relationships among visual assessments and mechanical properties, even within individual mulch treatments, it would be advisable to limit the use of visual assessments to mulch functionality, leaving mulch mechanical properties, among others, for the measurement of degradation.

\section{Literature Cited}

ASTM. 2006. Standard test method for breaking strength and elongation of textile fabrics (strip method). ASTM D5035-06. ASTM International, West Conshohocken, PA.

Blick, A.P., M.V.E. Grossman, and F. Yamashita. 2010. Biodegradable mulch films for strawberry production. Polym. Test. 29:471-476.

Briassoulis, D. 2004. An overview on the mechanical behaviour of biodegradable agricultural films. J. Polym. Environ. 12:65-81.

Briassoulis, D. 2006. Mechanical behaviour of biodegradable agricultural films under real field conditions. Polym. Degrad. Stabil. 91:1256-1272.

Briassoulis, D. 2007. Analysis of the mechanical and degradation performances of optimised agricultural biodegradable films. Polym. Degrad. Stabil. 92:1115-1132.

Candido, V., V. Miccolis, D. Castronuovo, S. Margiotta, and C. Manera. 2006. The effect of soil solarization and protection techniques on yield traits of melon in unheated greenhouse. Acta Hort. 710:415-420.

Cascone, G., A. D'Emilio, E. Buccellato, and R. Mazzarella. 2008. New biodegradable materials for greenhouse soil mulching. Acta Hort. 801: 283-290.

Cowan, J.S., C.A. Miles, P.K. Andrews, and D.A. Inglis. 2014. Biodegradable mulch performed comparable to polyethylene in high tunnel tomato (Solanum lycopersicum L.) production. J. Sci. Food Agr. 94:1854-1864.

Dharmalingam, S., D.G. Hayes, L.C. Wadsworth, R.N. Dunlap, J.M. DeBruyn, J. Lee, and A.L. Wszelaki. 2015. Soil degradation of polylactic acid/polyhydroxyalkanoate-based nonwoven mulches. J. Polym. Environ. 23:302-315.

Hablot, E., S. Dharmalingam, D.G. Hayes, L.C. Wadsworth, C. Blazy, and R. Narayan. 2014. Effect of simulated weathering on physicochemical properties and inherent biodegradation of PLA/PHA nonwoven mulches. J Polym. Environ. 22:417-429.

Hakkarainen, M. 2002. Aliphatic polyesters: Abiotic and biotic degradation and degradation products. Adv. Polym. Sci. 157:113-138.

Hayes, D., G.S. Dharmalingam, L.C. Wadsworth, K.K. Leonas, C. Miles, and D.A. Inglis. 2012. Biodegradable agricultural mulches derived from biopolymers, p. 201-223. In: K.C. Khemani and C. Scholz (eds.). Degradable polymers and materials: Principles and practice, 2nd ed. (ACS Symposium Series, Volume 1114). American Chemical Society, Washington, DC.

Hill, D.E., L. Hankin, and G.R. Stephens. 1982. Mulches: Their effects on fruit set, timing and yields of vegetables. Conn. Agr. Expt. Sta. Bul. 805.
Ho, K.G., A.L. Pometto, III, and P.N. Hinz. 1999. Effects of temperature and relative humidity on polylactic acid plastic degradation. J. Polym. Environ. 7:83-92.

Kenward, M. and J. Roger. 1997. Small sample inference for fixed effects from restricted maximum likelihood. Biometrics 53:983-997.

Kijchavengkul, T., R. Auras, M. Rubino, M. Ngouajio, and R.T. Fernandez. 2008. Assessment of aliphatic-aromatic copolyester biodegradable mulch films. Part I: Field study. Chemosphere 71:942-953.

Kirk, R.E. 1982. Experimental design: Procedures for the behavioral sciences. 2nd ed. Brooks/ Cole, Monterey, CA.

Klungland, M.W. and M. McArthur. 1989. Soil survey of Skagit County area, Washington. U.S. Dept. Agr. Soil Conservation Serv., Washington, DC.

Krzan, A., S. Hemjinda, S. Miertus, A. Corti, and E. Chiellini. 2006. Standardization and certification in the area of environmentally degradable plastics. Polym. Degrad. Stabil. 91:2819-2833.

Kyrikou, I. and D. Briassoulis. 2007. Biodegradation of agricultural plastic films: A critical review. J. Polym. Environ. 15:125-150.

Lamont, W.J., Jr. 1993. Plastic mulches for the production of vegetable crops. HortTechnology 3:35-39.

Lucas, N., C. Bienaime, C. Belloy, M. Queneudec, F. Silvestre, and J.E. Nava-Saucedo. 2008. Polymer biodegradation: Mechanisms and estimation techniques. Chemosphere 73:429-442.

Martín-Closas, L., A.M. Pelacho, P. Picuno, and D. Rodríguez. 2007. Biodegradable mulching in an organic tomato production system. Acta Hort. 801:275-282.

Martín-Closas, L., M.A. Bach, and A.M. Pelacho. 2008. Biodegradable mulching in an organic tomato production system. Acta Hort. 767: 267-274.

Miles, C., C. Beus, A. Corbin, R. Wallace, A. Wszelaki, H. Saez, T. Walters, K. Leonas, M. Brodhagen, D. Hayes, and D. Inglis. 2009. Research and extension priorities to ensure adaptation of high tunnels and biodegradable plastic mulch in the United States. p. 102-108. (Proc. 35th Natl. Agr. Plastics Congr).

Miles, C., R. Wallace, A. Wszelaki, J. Martin, J. Cowan, T. Walters, and D. Inglis. 2012. Deterioration of potentially biodegradable alternatives to black plastic mulch in three tomato production regions. HortScience 47: 1270-1277.

Minuto, G., L. Pisi, F. Tinivella, C. Bruzzone, S. Guerrini, M. Versari, S. Pini, and M. Capurro. 2008. Weed control with biodegradable mulch in vegetable crops. Acta Hort. 801:291-298.

Moreno, M.M. and A. Moreno. 2008. Effect of different biodegradable and polyethylene mulches on soil properties and production in a tomato crop. Sci. Hort. 116:256-263.

Moreno, M.M., A. Moreno, and I. Mancebo. 2009. Comparison of different mulch materials in a tomato (Solanum lycopersicum L.) crop. Span. J. Agr. Res. 7:454-464.

National Resources Conservation Service. 2010. Web soil survey. 12 Aug. 2010. <http:// websoilsurvey.nrcs.usda.gov/app/WebSoilSurvey. aspx>.

Ngouajio, M. and J. Ernest. 2005. Changes in the physical, optical, and thermal properties of polyethylene mulches during double cropping. HortScience 40:94-97.

Ngouajio, M., R. Auras, R.T. Fernandez, M. Rubino, J.W. Counts, Jr., and T. Kijchavengkul. 2008. 
Field performance of aliphatic-aromatic copolyester biodegradable mulch films in a fresh market tomato production system. HortTechnology 18:605-610.

Olsen, J.K. and R.K. Gounder. 2001. Alternatives to polyethylene mulch film - a field assessment of transported materials in capsicum (Capsicum annuит L.). Austral. J. Expt. Agr. 41:93-103.

Saxton, A.M. 2010. DandA.sas: Design and analysis macro collection version 2.11. Univ. of Tenn., Knoxville, TN. 17 Sept. 2013.

Scarascia-Mugnozza, G., E. Schettini, G. Vox, M. Malinconico, B. Immirzi, and S. Pagliara. 2006. Mechanical properties decay and morphological behaviour of biodegradable films for agricultural mulching in real scale experiment. Polym. Degrad. Stabil. 91:2801-2808.

Schonbeck, M.W. 1998. Effects of mulches on soil properties and tomato production I. Soil temperature, soil moisture and marketable yield. J. Sustain. Agr. 13:13-33.

Schonbeck, M.W. and G.K. Evanylo. 1998. Weed suppression and labor costs associated with organic, plastic, and paper mulches in small-scale vegetable production. J. Sustain. Agr. 13:55-81.

Shogren, R.L. 2000. Biodegradable mulches from renewable resources. J. Sustain. Agr. $16: 33-47$.
Shogren, R.L. and R.C. Hochmuth. 2004. Field evaluation of watermelon grown on paperpolymerized vegetable oil mulches. HortScience 39:1588-1591.

Takakura, T. and W. Fang. 2001. Climate under cover. Kluwer Academic Publishers, Dordrecht, Germany.

Tocchetto, R.S., R.S. Benson, and M. Dever. 2001. Outdoor weathering evaluation of carbon-black-filled, biodegradable copolyester as substitute for traditionally used, carbonblack-filled, non-biodegradable, high-density polyethylene mulch films. J. Polym. Environ. 9:57-62. 